\title{
Knowledge Production in a Cooperative Economy
}

\author{
ALAN COTTEY \\ School of Chemistry, University of East Anglia, Norwich NR4 7TJ, UK
}

\begin{abstract}
Knowledge here means something similar to but broader than science; reliable but not necessarily as systematic or explicit. A cooperative economy is contrasted with the competitive economy that has dominated political thinking almost everywhere for about half a century - the neoliberal period. It is argued that the neo-liberal ideology and its economic ideas and practices are unjust and unsustainable. A model for a cooperative economy is described which would be more just and sustainable. Three main features of the model are outlined - basic income, asset and income limits, and a concept of work that counts all activity useful to human well-being rather than counting monetary profit. Knowledge in such an economy is considered in four main stages production, review, dissemination and use. It is argued that, in the described cooperative economy, these stages would proceed more efficiently and lead to human well-being.
\end{abstract}

\section{Introduction}

This paper is organised into three main sections - a clarification of key terms, an outline of a cooperative scenario, and a discussion of how an open knowledge economy based on such a scenario might look. In society, there are two chief world systems, one competitive, the other cooperative. The former, currently dominant, is unjust and unsustainable. The latter, an unbroken thread through history, which has long been limited by human values and not by technology, could be relatively just and sustainable. The current economic difficulties of the competitive social system would play a much smaller role in a cooperative social system. In an economy with asset and income limits (AIL) and basic income for all, most of what is currently called 'work' would be unnecessary. Necessary production and routine organisation could be done largely by machines, giving humans more freedom. Some will exercise this freedom in the production, dissemination and application of knowledge. In this paper, the focus is mainly on the initial production and testing of knowledge.

The economic and psychological security provided by a cooperative social system would permit humans and their institutions to be more relaxed about priority and property (including intellectual property) and to take part in the development of knowledge in a more open way than at 
present. The ideology of knowledge as common heritage, recently weakened, would be restored and extended. To be sure, elements of competitiveness will remain. Two of these are specially relevant for knowledge production. One of these is competition for access to equipment, peers and the attention of a discriminating audience; there have to be valid means of establishing reputation. The other is that humans have a desire for the approbation of others, which is no doubt deeper even than that inculcated during millennia of pronounced hierarchy and competition. This desire can be accommodated in benign ways which are not monetary and not transferable and they are described in this paper. A further feature of the proposed model is the foregrounded recognition that knowledge development has many stages and is multi-faceted. The present emphasis on (supposedly discrete) discovery impedes a proper appreciation of this complexity. In this paper, that complexity is addressed. Appropriate ways of acknowledging all roles are suggested. For example, the role of referees is important but the currently usual method of anonymous refereeing of resource applications and of manuscripts is flawed and could, in a cooperative system, be replaced by open, acknowledged referee reports. A full history of a project, from proposal to publication and subsequent commentary and use, could be open. As far as practicable, all significant or potentially significant elements, including data, summarised when appropriate, would be archived as they occur. Even in the current state of the art of digitising and mass storage, this could be done to an impressive extent. Basic world standards of data handling are already largely in place but this does not require the archiving itself to be centralist. In this way, well-established knowledge would emerge gradually with the many inputs being openly acknowledged and given their due weight. Over time, a widely comprehensible corpus of core knowledge would emerge which would be more reliable and more cross-cultural; less history written by winners. Various elements of this overall proposal have been put forward frequently and some put into effect or at least trialled. Common objections to the proposal are discussed. The paper ends by emphasising that the changes now needed are changes of human values. The technological and organisational methods are already in place.

\section{Clarification of key terms}

There are some key terms in this article which seem straightforward if considered simplistically but which in fact are used in different ways by apologists of various points of view. The main ones are science, knowledge, openness, economics and cooperation. I hope the reader will discern from the following subsections how I use these terms and 'where I am coming from'. No attempt at 'dictionary definitions' will be made as these would be inadequate. 
In this article I will mean by knowledge a fairly modest extension of what is normally meant by science, so that, for example, evidence-based history is included. The boundary between science and knowledge is fuzzy and I wish not to exclude any knowledge that is evidence-based merely because of conventional subject labels. For a discussion of knowledge in relation to work, law and property, see Scranton (2012). On science and knowledge, see Ravetz (1971). Human knowledge and power over nature have increased gradually over millennia and longer but especially in the modern era. This is generally celebrated, but the problematic sides - unintended consequences and misuse of power - are often ignored or denied. On 'science for good or ill', see Davis (1990); on inattention and denial see Norgaard (2011).

\section{Openness}

Openness in human relationships is generally considered a virtue and to have positive consequences. Unqualified advocacy of openness is however naive. Bok (1982) has produced in Secrets: on the ethics of concealment and revelation a nuanced philosophical study of openness and its converse. A critique in a similar spirit, on Secrecy and Transparency, is given in a special section of Theory, Culture and Society, edited by Birchall (2011). In Openness, Confidence and Trust in Science and Society, I discuss the essential conditions for a high level of openness in human relations generally, and in science particularly (Cottey 2010). The high level of trust which exists already in society, but is often overlooked in the attention to sensational breakdowns, is discussed in depth in Schneier (2012). This helps to show that the kind of cooperative economy I discuss in this paper is not so far removed from many aspects of present practice as may at first be supposed.

While the tension between openness and various contrary characteristics (secrecy, censorship, self-censorship, privacy, repression, etc) is age-old, a particular recent period merits special mention, namely the 1960s. Around this decade liberal culture (in the US and broadly similar cultures) took a decisive turn against a traditional automatic respect for established authority. This was manifest in many events and developments. These include the passage of freedom of information law, first in the US and gradually in other countries with similar ideologies (pp173-174 of Peters 2009a); the experiments of Milgram (1975) on Obedience to Authority, performed in the years 1960-1963 (ibid, p xv) and reported in several papers from 1963 to 1972 (ibid, p216); the anti-establishment unrest of workers and students in Europe and the US around 1968; the higher profile of whistleblowing cases, increased awareness of the problems of reprisals and the need for discriminate protective legislation - see for example Whistleblowers Australia (2012). The changes of this period have been permanent (so far!) in the sense that no full return to the earlier ethos has occurred, notwithstanding subsequent reactions from powerful institutions. Overall, one may say that the ante has been raised. One example is the protracted political struggle 
over the public release of information relating to the death of British weapons expert Dr David Kelly, a few months after the start of the 2003 invasion of Iraq (Halpin 2013).

\section{Open science}

Openness has been part of the ideology of science from the beginning of the modern period (even before the term science was used, the project being called natural philosophy), that is, from around the 17-th century (David 2008, Eamon 1985). The 'new philosophy' - observing the world and disseminating and criticising the findings - presented a profound challenge to the long-established ideology of respect for authority. It is not easy, from within our culture, now, to appreciate how great was this challenge. An appreciation of it gives us some understanding of what otherwise is quite mysterious - why did it take so long, getting on for two millennia, for the proposition that the earth moved round the sun, suggested already by Aristarchus [310 BCE - ca. $230 \mathrm{BCE}$, to be generally accepted as the chief world (physical) system? This became generally accepted only after mounting evidence, culminating in the work of Galileo [1564 - 1642], rendered the Ptolemaic and Tychonic (a compromise) systems wholly untenable. In his popularisation Dialogue Concerning the Two Chief World Systems, Galileo (1632) attended carefully to the arguments of the sceptics and put his case as straightforwardly as possible and in Italian not Latin. He was dealing with a deep level of denial by the conservative philosophers and theologians, as is always the case when an elephant in the room is ignored. And if someone should commit the solecism of drawing attention to it, the response is likely to be irrational - denial, defensiveness (Zerubavel 2006) and possibly reprisals in the form of ridicule, ostracism and worse (Calland and Dehn 2004; pp211-213 of Bok 1982).

While the thread of openness in science has been continuous since the 17-th century, the term open science has taken on a new and distinctive significance in the last few decades (Nielsen 2009, Peters 2009a, Peters 2013). I refer to a synergy between the general move to increased openness in liberal cultures, as mentioned at the end of the preceding section, and new possibilities in information technology (IT). The notion of open source software took off, developing at first gradually in the 1980s and then into a coherent and legally defensible system especially with the General Public Licence and subsequent refinements - see, for example, Feller et al (2005). This led to a radicalisation of the traditional concept of openness in science, so that proposals for open research are made and relatively small scale experimental initiatives undertaken - for example, Bradley (2007), De Roure (2010). Technologies are, however, always two-edged. IT has also been used to create huge secret collections of personal data - see for example Ashdown (2013).

\section{Economics}

In Galileo's Dialogue the two chief world systems he referred to were systems of the physical world. Today, there is no controversy of comparable intensity about the nature of the physical world 
and scientists can propose ideas with relative impunity. A guiding assumption in the present paper is, however, that there are currently two chief economic systems and that the tension between them is as intense as that in the controversy between the two physical systems in which Galileo played an important part. Indeed, I could have written ' two chief social systems' with almost the same meaning, so deeply has economic thinking penetrated current society. These two chief economic systems I label competitive and cooperative.

Competition: We know from world history a good deal about competition - see, for example, Roberts and Westad (2013). Evidence from pre-history is scarcer (Roberts and Westad 2013) but the last five millennia is enough for the present purpose. History takes us back more-or-less to the beginning of civilisation, that is, the large-scale adoption of agriculture and the invention of writing. These developments gave competitive elites the ability to concentrate surpluses and power, to build and control cities; and then to maintain armies and establish empires. The large-scale economic structures were and are strongly hierarchical, unequal and exploitative (Graeber, 2012). Such societies are ruthlessly competitive. In more recent centuries it is thought necessary to claim that such competition is free and fair, whereas in fact it is usually neither - see for example p38 of Shutt (2010).

Cooperation: All of this has been achieved in a social setting that involves much cooperation at a personal level and local level. If we fast forward to the last few centuries, we find the emergence of ideas of equality and democracy, ideas which gradually gained ground - until roughly half a century ago, since when competition and inequality have again increased. Nevertheless cooperation in dayto-day life continues, often automatically and unnoticed. Its vital role is exposed in the studies of Dolšak and Ostrom (2003), McKibben (2007), Ostrom (1990), Ostrom and Ahn (2003), Poteete, Janssen and Ostrom (2010), Schneier (2012).

\section{Ecology}

Nothing beside remains. Round the decay

Of that colossal Wreck, boundless and bare

The lone and level sands stretch far away. (Leader and O'Neill 2003, p198. lines 12-14 of P. B. Shelley's Ozymandias)

Many civilisations have risen and fallen. See, for example Collapse: how societies choose to fail or survive (Diamond 2011). Hitherto, there were always 'barbarians' elsewhere who filled the power vacuum. The present situation is new, in that the ecological limits of the planet have been reached, 
or perhaps already surpassed. Thus a general collapse of the present economic order (and I discount here mere business cycles) is a distinct possibility. Indeed, in view of the continued desire of business leaders, politicians and the mass media for further growth at the rate of a few percent per year, this can be considered a likely outcome. Although these dire assertions are in line with the views of many well-informed scientists and intellectuals, for example Beddington (2009), Kempf (2008), (McNutt 2013), Rees (2003), it has to be admitted that they are not accepted by many and they are acted on by very few indeed, even those who accept the analysis intellectually. Here, then, lies an important element (the other is justice) of today's struggle between two world economic systems. In Why we Disagree about Climate Change: understanding controversy, inaction and opportunity, Hulme (2009) addresses this controversy directly.

\section{Creativity, imagination, courage, utopias}

Paradoxically, utopian writing may be the most realistic literary genre and utopian politics the most effective agent of social change. (Neville-Sington and Sington, 1993, p xii)

The gross exploitation of the inanimate and animate (including human) world demands an adequate response, not a slightly restrained business-as-usual such as has been the actual 'progress' of the recent period (half-century). The basic controversy is between a competitive and a cooperative economy. Relative to the 'solutions' offered by business, politicians and the mass media, adequate proposals appear radical and utopian. Yet major changes in society have happened in the past, often an unexpected cracking of the ice after a long freeze. Thus ended the bipolar Cold War. What is needed for our present problems is not growth of Gross Domestic Product (GDP) but growth of creativity, imagination and courage. A radical change to a new kind of economy could come to pass as a result of a major shake-up of the earth's ecology. We humans cannot predict in detail how evolutionary changes will proceed in these early stages of the anthropocene era but we continue to develop our understanding in the most relevant areas. For example, the journal Science has a special section on Natural Systems in Changing Climates (McNutt 2013). As will be argued in the following, the key factor is to apply our knowledge wisely.

\section{Values}

Prospects for the future are alarming but uncertain. Denial or inattention are tempting (Norgaard 2011). Prudent planning is necessary. There is yet another aspect of the current situation, namely that the present situation is unacceptable - see, for example, Drèze and Sen (2013), Kempf (2008). This is a value statement but so is the commitment to economic growth. The fundamental change needed is a change of values. Nevertheless, scientific knowledge is powerful - for good or ill. I will argue that it is more likely to be a force for good in a mainly cooperative economy than in a mainly competitive economy; further, that useful and beautiful knowledge can be produced more 
efficiently this way.

\section{A Cooperative Scenario}

If a just and sustainable civilisation is to be achieved, the distribution of economic and social power, which is currently grossly unfair and in some ways getting worse (Drèze and Sen 2013) must be radically changed. The historical and possible future development of science and technology have a role to play, not only through their cultural and practical fruits but also as a model of a commons (Nelson 2003). In this section I present a scenario for a possible cooperative economy. It is offered as a model, with three elements, concerning basic income, asset and income limits (AIL) and work. Some aspects of the model are described more fully in Cottey (2013). I have attempted as conservative a model as can be adequate to our situation. It is agnostic in respect of many other features. Thus

- it might have a mainly secular or a mainly sacred orientation

- concerning ideas about what exists, it might be spiritual or materialistic

- it could be compatible, in some areas, like the arts, with a high degree of individualism

- its government might conform to any of several models

- its legislative and judicial systems might conform to any of several models

- true, the culture could not be capitalist in the traditional mode, but it could be 'capitalist without large owners or shareholders and with strong restraints on the growth imperative'. Thus the model could be supportive of genuinely fair trade and of small businesses.

The model does however insist on a fundamental principle which will underly any civilised modern society, namely

every human must and can have ready access, essentially unconditional and by right, to the means of living a sufficient and dignified life.

This principle leads to the first of the three main features of the model -

\section{Basic Income}

Assuming that the model involves a monetary economy for at least some of the means of living a sufficient and dignified life, there has to be in place some kind of basic income system. Broadly similar proposals come under various names, including Citizen's Income and Negative Income Tax. 
See, for example, Ackerman et al (2006); Citizen's Income Trust (no date); Raventós (2007). The term 'unconditional' in the fundamental principle means that the income is paid to every person - regardless of how much they may possess by way of other income and of assets

- regardless of whether they attempt to gain other income

- and regardless of the person's domestic arrangements.

The amount will however depend on the person's needs. Those not competent to handle their own affairs (children, the demented, some others) will have a guardian to whom the basic income will be paid.

\section{Income and Asset Limits}

In recent years the excesses of unlimited accumulation are bemoaned in general discourse and in the mass media yet constructive suggestions rarely follow. There is a sense of impotence. More extensive analyses of the facts and problems can, however, be found in, for example, Battersby et al (2012), Brown (2002), Collins (2012), Cottey (2000a), Duchrow and Hinkelammert (2004), Forbes (no date), Kempf (2008), Pizzigati (2004), Rifkin (2000). Currently most states allow their citizens unlimited accumulation, a principle set out explicitly by Locke (1690) and widely endorsed ever since. On this, C B Macpherson in The Political Theory of Possessive Individualism commented the whole [of Locke's] theory of property is a justification of the natural right not only to unequal property but to unlimited individual appropriation. (Macpherson ,1962, p221)

In Cottey (2000a) and briefly in section 4.4 of Cottey (2013) I describe a way in which a (circumstance-dependent) maximum income could be administered. The first question that most people ask, on being presented with the notion of maximum income is 'how much?' but this is not the important point, apart from the fact that is should be sufficiently small as to be sustainable, that is, to allow civilisation to proceed. More important is that the proposal is not a $100 \%$ tax of incomes over the limit. Rather, excess income should be socially deviant, in our values, our customary laws and our legislation. What people mostly desire is self-respect and the respect of others. This need not translate into money. Several other kinds of benign reward for talent or industry are available and highly prized, as elaborated in the references given above.

Work

We now examine one of the most misused words in general discourse and especially in economic discourse - work. If by work we mean activity useful in sustaining a good life, much of what is generally called work is not work at all. Further, a large part of real work - useful activity - is not 
counted in economic discourse about work. What activity is necessary or useful? First, something which many spiritual teachers have long known to be fundamental - breathing. In case this should not seem like work, consider two cases, one a new-born baby, the other a sick person with a respiratory problem. The baby does not wait for someone to help it, although in practice some help is usually forthcoming; it does for itself what it can - it cries out. The sick person, likewise, may likely have help from others, but still, himself or herself, does what is possible, and in this case, it is hard work. Then everyone needs food and drink and they, including the baby, look after themselves as well as they can but are helped by others, people who care not only for themselves but also for others. All of these actions are of little or no account to a conventional economist but they are among the most fundamental actions that sustain a good life.

Consider, by contrast, what normal discourse calls work. It is generally paid employment, that is, selling one's labour. Normal discourse also includes self-employment and the management of others. Much of these kinds of work is unnecessary and in many cases even acts against the achievement and maintenance of a good life for all. A lot of such work is aimed against competitors and against laws which try to restrain the worst excesses of anti-social profiteering. There is also an army of people managing other people so as to maintain this inefficient culture of employment and unemployment. Further, those who obtain - the word earn is inappropriate - the largest incomes are among those who do the greatest harm, by obstructing positive change and by their central involvement in the most pernicious practices, notably speculation on a gigantic scale (Shutt 2010; passim, especially p14-20). It is a sign of the immorality of these practices that the most necessary goods, such as food, energy and shelter, are subject to intense speculation and prices are highly unstable, especially for the poorest. Meanwhile, many others are not even able to sell their own labour, even at a low price, and suffer multiple disadvantages - see, for example, Drèze and Sen (2013).

In case the claim that most so-called work is useless or even harmful should be thought an exaggeration, I point out that not much heavy or repetitive work has to be done by humans (Burke and Rumberger 1987, passim; Roberts 1982). This situation has existed for half a century at least. There have long been no technical reasons why most heavy and repetitive work should not be done by machines and computers. The obstacles to achieving this situation are cultural. There is, to be sure, need for work by humans, and it includes some healthy physical activity. The most needed work requires courage and application but only part of it is conventional employment. Apart from the caring for oneself and others, which is currently undervalued, there is need for thought, imagination and experiment (personal, domestic and political) in transcending the current culture and taking advantage of the possibilities before our noses. A thorough re-thinking of what is meant 
by work would render the basic income and maximum income proposals entirely practical. The objection 'all very nice but completely unaffordable' is grounded in business-as-usual economics and is specious. In a cooperative economy there could be rational use of machines and computers, abolition of structural unemployment, and the loss of a great swathe of bureaucracy (that part directed at present to maintaining gross inequality and unsustainable growth). Then all necessary public provisions, including basic income, could be funded through fairly modest taxation.

\section{Open Knowledge Economy}

Having explained what I mean by a cooperative economy, I can now turn to ideas on how knowledge might be efficiently produced, disseminated and used in such an economy. Obviously, such an economy, as described, differs greatly from the current ambience within which knowledge is produced, etc. The case for considering this scenario, different as it is from the current situation, is twofold: (i) it is intrinsically attractive, (ii) radical changes of some kind are afoot, as mentioned in the section on ecology, so it makes sense to consider whether we can take advantage of the adage 'crisis = opportunity'. Issues related to the present study are discussed in 'Neoliberalism, higher education and the knowledge economy' (Olssen and Peters 2005), in 'Knowledge economy, development and the future of higher education' (Peters 2007) and 'Open Education and the Open Science Economy' (Peters 2009b).

\section{Open Knowledge Production}

In almost all parts of the current competitive economy (and society) there is great emphasis on individual achievement, status and gain. Knowledge production is no exception. One consequence of this is what Frank and Cook (1995) call The Winner-Take-All Society. (The book is based on US society but its message applies more-or-less everywhere.) It relates to the growing inequality discussed earlier and also to the importance of celebrity in society. Most of us appear to need a small group of heroes or at least celebrities. They have to be sufficiently few and widely known to be the subject of gossip with fellow specialists and general conversation with friends and acquaintances. For the individual, this renders manageable the otherwise overwhelming complexity of modern society. Even in highly specialised areas of scientific research, where reputation is supposed to be built up among a peer-group of cognoscenti there is the Matthew Effect, named by Merton $(1968,1988)$ after the biblical passage "For unto every one that hath shall be given, and he shall have abundance: but from him that hath not shall be taken away even that which he hath." (Matthew 1953). The contributions of the obscure are unrecorded in favour of a simplified account naming one leader, or at most a few. 
In formal knowledge production by professionalised researchers, there is a reward structure identified by English (2005) as an economy of prestige. Even in today's money-oriented culture, approbation and respect are very important to those most creative in knowledge production. Selfrespect and the private joy of creation or invention, be it ever so humble, also matters to many. The remarks made about rewards, briefly in the section Income and Asset Limits and more fully in Cottey 2000a, apply to knowledge producers even more than to many other members of society. In a cooperative economy, the manifold inputs into the production of new knowledge would be taken for granted. Struggles and worries over priority and credit would play a smaller role. Nevertheless, a detailed record of who did what and when would be possible through an Open knowledge schema (Cottey 2003) or, in the case of what is conventionally known as science, an Open science protocol (Cottey 2000b).

\section{Open, Comprehensive, Inclusive and Ongoing Review}

Those formally and professionally engaged in knowledge production are rightly much exercised by quality assurance. How to filter out poor offerings? The principal method used is known as peer review. This term is often used without much thought by many practitioners, who just get on with production. Peer review is claimed to be efficient; it has its occasional failures, but of course no system is perfect and the price of the occasional lapse is much less than the value of the overall output. This characterisation of the process of review is simplistic, conservative (aims to maintain the status quo) and self-serving. In fact peer review proper is but a part of much larger production process which typically involves (in best practice)

- private thought by one or a few individuals

- consultation with selected peers

- development of a project plan

- negotiation with employing institution managers and administrators

- application for funding

- consideration by funding bodies

- peer review of funding application

- if, after some attempts and modifications, a funding application is successful, further negotiations with the institution may ensue

- hiring of staff (more peer review here); purchase and/or building equipment

- conducting the project (with periodic reports, reviews, adaptations) 
- preliminary reports (probably first to selected peers, then to a conference, then to a preprint repository)

- formal report, for the record, submitted for publication in a recognised and archival specialist e-journal or print journal

- consideration of the submission by editor

- if the submission passes this hurdle it goes to what most people understand by 'peer review', that is criticism by other specialists in the field, selected by the editor

- if the submission passes this hurdle, usually after revision, it is published and that is a natural endpoint of a filtering process but not the end of the knowledge production, which continues with dissemination and use.

Before turning to them, I will make some points, some of which refer to the above filtering process and some more generally. The first is that the filtering process is at several stages quite secretive. Anonymity and lack of accountability are fertile grounds for the mis-use of power (pp30-41 of Calland and Dehn 2004; pp105-107 of Bok 1982). The secrecy elements of the filtering process are widely supported in the professional knowledge production community and are justified by the argument that anonymity promotes frank and honest criticism. In many cases indeed referees are constructive, spotting mistakes or suggesting improvements. At the same time most authors believe that anonymity does permit some poor refereeing to occur. Sometimes it is apparent that the referee has not understood the submission and sometimes appears to be unjustly hostile. Another class of defective refereeing, which cannot be written off as author hypersensitivity, is when the referee appears to have let the paper through on the nod. Another defect in refereeing which is common in the current situation, and is indefensible, is when the referee sits on the paper despite having been given an adequate amount of time. This is presumably related to the fact that referees are, in the present dispensation, asked to give time to the paper without any apparent reward. Whether a referee responds promptly is a matter of chance. I emphasise 'apparent' because there are two less overt rewards. One is seeing papers in advance of others. There is a considerable amount of paranoia about this, perhaps more than is justified. The second reward is less often noted and probably more important. It is part of entry into the specialist peer group. Similar remarks apply also to refereeing grant applications.

All of the steps discussed above are influenced by the ambient culture and the formative cultures of all concerned. Importantly, most of these steps are far from open and some are highly secretive. The whole process is remarkably efficient at generating knowledge useful to, or safe for, 
states and corporations but there is a major problem, which was concisely expressed by the engineer, astronomer and physicist Martin Ryle

Our cleverness has grown prodigiously - but not our wisdom. (Rowan-Robinson and Rudolf, 1985, p20; also Rudolf and Rowan-Robinson, 1985, p37)

Thus we have arrived at a situation in which investment of excess capital takes precedence over the most basic needs of people (Drèze and Sen 2013, Duchrow and Hinkelammert 2004, Shutt 2010). To be sure, knowledge production is not solely responsible for this state of affairs but it is embedded in the current competitive and exploitative economy.

How might knowledge production be different, if embedded in a cooperative economy? This is a large question and I will address principally one aspect of it, namely the possibility of Open, Comprehensive, Inclusive and Ongoing Review. Currently, openness of the review process alarms most of those involved. Objections about embarrassment or retribution are voiced. In a cooperative economy, however, openness would not be a problem. In the first place, open criticism will offered in a measured, reasoned manner. Secondly, for authors to be exposed as having made a mistake in a submitted draft, or for grant applications to have been rejected, will not be a great embarrassment. It happens to everyone. Openness will motivate submitters, reviewers and editors to perform their tasks well. They require considerable time, effort and skill. These tasks are important, a significant part of the whole knowledge production process. Their costs should be built explicitly into the economics (in the broadest sense) of knowledge production. In particular, reviewers should should be openly and explicitly rewarded for their contributions. As explained in the section on Asset and Income Limits the reward need not, and probably should not, be primarily in the form of personal honorarium. More important is recognition and respect in the peer group and in employing and professional institutions. This occurs at present but generally in a shadowy way. Why not bring it into the light?

Next, what is meant by comprehensive review? The point here is that peer review suffers a defect closely related to its very strength. It takes decades of hard work to become an expert. It requires focus on an ever more specialised area, for the gold standard is 'an original contribution'. In a world with perhaps a billion fairly highly educated people and millions of scholars, specialisation reaches an extreme level. This is how we become, as Martin Ryle indicated in the quotation above, prodigiously clever but not wise. (See also Barnet and Maxwell 2008; Cottey 2012, Davis 1990, Maxwell 2007.) The peer group has its own interests and by virtue of the arduous rites of passage and the specialisation, they are not the same as the public interest. These interests can indeed diverge widely. The solution to this problem is to make the review process comprehensive, that is, to represent all interested parties. The parties are not equal. This is not a problem, rather a virtue. 
The expertise of specialists must be respected. Yet it needs to be supplemented by inputs from other constituencies. These might, depending on the circumstances, include - scholars from adjacent specialities who have a 'nose' for the subject but are less affected by the narrow peer group's interests; representatives of the cooperative economy (this will include administrators and politicians); ethicists; representatives of those who may be most affected by likely use of the knowledge (especially those from non-industrialised cultures who currently tend to lose out). Each constituency would have a brief and a weight appropriate to its role. Only a few major projects would be subjected to so heavy a review as to include all of the above constituencies. The aim is to make knowledge production more democratic and more oriented toward living with the earth and sustaining human culture.

'Inclusive' is included in the subsection heading above to make it clear that comprehensive does not just apply to technical breadth but embraces the inclusion of human groups with an interest who may otherwise be excluded. Likewise, 'Ongoing' means that the review process does not end with publication but continues with dissemination (on which more below) and further comment, leading eventually, for the most well-established and useful work (intellectually and practically), to incorporation in an informal corpus of generally accepted reliable knowledge.

\section{Open Knowledge Dissemination}

It is not necessarily enough to get a project past the funding, execution and publishing stages. It must be disseminated. So much material is now published, especially since the introduction of 'publication for all' via the internet, that further filtering is needed if the world store of reliable and valuable knowledge is to be enhanced. This does not simply mean adding new knowledge. It also means refinement, simplification and consolidation. In this way the obscuring blizzard of data, information (not the same thing as knowledge) and disinformation, a feature of the present times, may pass. See Ravetz 1971 for discussions of scientific knowledge (pp 69-240), information (pp 8388 ) and data (pp 76-83). For a relentless exposé of disinformation, see Kick (2002) and, for balance, a measured account of trust by Schneier (2012). The current arrangements for dissemination of knowledge are in a state of ferment and are the subject of lively debate (for example, Banks 2013, Haspelmath 2013) and experimentation (for example, Bradley 2007, De Roure 2010).

\section{Open Knowledge Use}

This article is primarily about knowledge production but as its use is inseparable it is necessary to say a few words here. Knowledge is evidently connected with power, although the adage 'knowledge is power' is simplistic and open to different interpretations. Ravetz (1990) in 'The Merger of Knowledge with Power' provides an extended nuanced discussion. Knowledge producers are specialists and they possess small areas of specialised knowledge. In the current competitive 
economy (and global society), growing economic inequality goes with growing inequality of power. The individuals and institutions with great economic and social power have access to knowledge (as well as information). They also have the ability to select and disseminate information and so to shape what is generally accepted as 'knowledge' but is something less than the reliable scientific knowledge discussed here.

How would the use of knowledge in a cooperative economy differ from that in the current competitive economy? If the obfuscation currently widespread, especially in economic discourse (see for example pp 11-34 of Kick 2002), were rendered obsolete, the disorder of information and disinformation would abate and people could see and attend to what is really important - justice and sustainability. Discovering what truly does contribute to these vital qualities is the principal use to which reliable knowledge should be put (Cottey 2012, Barnett and Maxwell 2008, Maxwell 2007). Using knowledge in this way amounts to wisdom.

\section{Acknowledgements}

I acknowledge with thanks comments on drafts of this paper by R Jennings, K Lam, N Maxwell, F Oeser, P Pickbourne, H Shutt and A Spense.

\section{References}

Ackerman, B., Alstott, A. \& van Parijs, P. (2006) Redesigning Distribution: basic income and stakeholder grants as alternative cornerstones for a more egalitarian capitalism. London: Verso.

Ashdown, P. (2013) NSA Surveillance: who watches the watchers? The Guardian, 12 June www.theguardian.com/commentisfree/2013/jun/12/nsa-surveillance-who-watches-watchers (accessed 26 August 2013).

Banks, M. (2013) The Reality of Open Access, Physics World, 26(8), 22-27.

Barnett, R. \& Maxwell, N. (2008) Wisdom in the University. London: Routledge.

Battersby, S., Else, L., George, A., Norton, M. I., Pearce, F. \& Rogers, D. (2012) The Age of Inequality, New Scientist, 215(2875), 37-45.

Beddington, J. (2009) The Perfect Storm. Government Office for Science http://www.bis.gov.uk/goscience/news/speeches/the-perfect-storm (accessed 26 August 2013).

Birchall, C. (Ed) (2011) Secrecy and Transparency, Theory, Culture and Society, 28(7-8), 3-172. 
Bok, S. (1982) Secrets: on the ethics of concealment and revelation. New York: Pantheon.

Bradley, J-C. (2007) Open Notebook Science Using Blogs and Wikis.

http://precedings.nature.com/documents/39/version/1/files/npre200739-1.pdf (accessed 26 August 2013).

Brown, D. (2002) Insatiable is not Sustainable. Westport: Praeger.

Burke, G. \& Rumberger, R. W. (Eds) (1987) The Future Impact of Technology on Work and Education. London: Falmer Press.

Calland, R. \& Dehn, G. (Eds) (2004) Whistleblowing Around the World: law, culture and practice. Cape Town: Open Democracy Advice Centre; and London: Public Concern at Work.

Citizen's Income Trust (no date) Citizen's Income. www.citizensincome.org (Contains much downloadable material;.accessed 26 August 2013).

Collins, C. (2012) 99 to 1: how wealth inequality is wrecking the world and what we can do about it. San Francisco: Berrett-Koehler.

Cottey, A. (2000a) Asset and Income Limits for individuals are needed, if the trend to ever greater consumption is to be reversed. www.uea.ac.uk/ c013/ail/ail.html (accessed 26 August 2013).

Cottey, A. (2000b) The Open Science Proposal - an outline of open science, with a section on the relevance of IT. www.uea.ac.uk/ c013/open_science/open_science.html (accessed 26 August 2013).

Cottey, A. (2003) Open Knowledge, SGR Newsletter, Issue 26, 17-18. Available also from http://www.sgr.org.uk/publications/sgr-newsletter-no-26 (accessed 26 August 2013).

Cottey, A. (2010) Openness, Confidence and Trust in Science and Society, International Journal of Science and Society, 1(4), 185-194. Also e-print available from http://ijy.cgpublisher.com/product/pub.187/prod.68 (accessed 29 August 2013).

Cottey, A. (2012) The Wisdom of Sages: nuclear physics education, knowledge-inquiry, and wisdom-inquiry, Policy Futures in Education, 10(5), 587-593.

Cottey, A. (2013) Technologies, Culture, Work, Basic Income and Maximum Income, AI \& Society: journal of knowledge, culture and communication. DOI: 10.1007/s00146-013-0480-0 . 'Online First' on SpringerLink: link.springer.com/article/10.1007\%2Fs00146-013-0480-0 (accessed 26 August 2013).

David, P. A. (2008) The Historical Origins of 'Open Science': an essay on patronage, reputation and 
common agency contracting in the scientific revolution, Capitalism and Society, 3(2), ii-103.

Davis, C. (1990) Science for Good or Ill. Santa Barbara CA: Nuclear Age Peace Foundation.

De Roure, D. et al (2010) Towards Open Science: the myExperiment Approach, Concurrency and Computation: Practice and Experience, 22(7 July), 2335-2353. DOI: 10.1002/cpe.1601 .

Diamond, J. (2011) Collapse: how societies choose to fail or succeed. London: Penguin. [Note: this is the same as the 2005 edition apart from an added afterword, pp 526-539, on the Angkor's decline.]

Dolšak, N. \& Ostrom, E. (2003) The Commons in the New Millennium: challenges and adaptations. Cambridge, MA: MIT Press.

Drèze, P. \& Sen, A. (2013) An Uncertain Glory: India and its contradictions. London: Allen Lane.

Duchrow, U. \& Hinkelammert, F. J. (2004) Property for People, not for Profit. New York: Zed Books.

Eamon, W. (1985) From the Secrets of Nature to Public Knowledge: the origins of the concept of openness in science, Minerva, 23(3), 321-347.

English, J. F. (2005) The Economy of Prestige: prizes, awards, and the circulation of value. Cambridge MA: Harvard University Press.

Feller, J., Fitzgerald, B., Hissam, S. A. \& Lakhani, K. R. (Eds) (2005) Perspectives on Free and Open Source Software. Cambridge MA: MIT Press.

Forbes (no date) The World's Billionaires. Forbes. www.forbes.com/billionaires . (accessed 26 July 2013).

Frank, R. H. \& Cook, P. J. (1995). The Winner-Take-All Society. New York: Free Press.

Galileo, G. (1632). Dialogue Concerning the Two Chief World Systems - Ptolemaic and Copernican. [The English edition of 1962 has a foreword by A Einstein and a preface by translator and editor S Drake.] Berkeley CA: University of California Press.

Graeber, D. (2012) Debt: the first 5000 years. Broooklyn NY: Melville House.

Halpin, D. (2013) Dr David Kelly dhalpin.infoaction.org.uk/23-articles/dr-david-kelly (accessed 26 August 2013).

Haspelmath, M. (2013) Why Open-access Publication Should be Nonprofit - a view from the field of theoretical language science, Frontiers in Behavioural Neuroscience, 06 June, 1-3. DOI: 10.3389/fnbeh.2013.00057 . 
Hulme, M. (2009) Why we Disagree about Climate Change: understanding controversy, inaction and opportunity. Cambridge: Cambridge University Press.

Kempf, H. (2008) How the Rich are Destroying the Earth. Totnes UK: Green Books.

Kick, R. (Ed) (2002) Everything You Know is Wrong: the disinformation guide to secrets and lies. New York: The Disinformation Company.

Leader, Z. \& O'Neill, M. (Eds) (2003) P B Shelley: The major works. Oxford: Oxford University Press.

Locke, J. (1690) Second Treatise of Government. Project Gutenberg. www.gutenberg.org/ebooks/7370 (accessed 26 August 2013).

McKibben, B. (2007) Deep Economy: the wealth of communities and the durable future. New York: Henry Holt.

McNutt, M. (2013) Natural Systems in Changing Climates, Science, 341(6145), 435 and 472-524.

Macpherson, C. B. (1962) The Political Theory of Possessive Individualism: Hobbes to Locke. Oxford University Press, Oxford.

Matthew (1953) The Gospel According to St Matthew, 25:29, in Anonymous Scholars of the Church of England, The Holy Bible: authorised King James version. Oxford, Oxford University Press. (Reprint; first published 1611). Also available at biblehub.com/kjv/matthew/25-29.htm (accessed 26 August 2013).

Maxwell, N. (2007) From Knowledge to Wisdom, 2nd edition. London: Pentire Press.

Merton, R. K. (1968) The Matthew Effect in Science, Science, 159 (3810), 56-63. Also available at www.garfield.library.upenn.edu/merton/matthew1.pdf (accessed 26 August 2013).

Merton, R. K. (1988) The Matthew Effect in Science, II: Cumulative Advantage and the Symbolism of Intellectual Property, ISIS, 79, 606-623. Also available at garfield.library.upenn.edu/merton/matthewii.pdf (accessed 26 August 2013).

Milgram, S. (1975) Obedience to Authority: an experimental view. New York: Harper \& Row.

Nelson, R. R. (2003) The Advance of Technology and the Scientific Commons, Philosophical Transactions of the Royal Society of London Series A, 361(1809), 1691-1708.

Neville-Sington, P. \& Sington, D. (1993) Paradise Dreamed: how utopian thinkers have changed the modern world. London: Bloomsbury

Nielsen, M. (2009) Doing Science in the Open, Physics World, 22(5), 30-35. 
Norgaard, K. M. (2011) Living in Denial: climate change, emotions, and everyday life. Cambridge MA: MIT Press.

Olssen, M. \& Peters, M. A. (2005) Neoliberalism, Higher Education and the Knowledge Economy: from the free market to knowledge capitalism, Journal of Education Policy, 20(3), 313-345.

Ostrom, E. (1990) Governing the Commons: the evolution of institutions for collective action. Cambridge: Cambridge University Press.

Ostrom, E. \& Ahn, T. K. (Eds) (2003) Foundations of Social Capital. Cheltenham UK: Edward Elgar Publishing.

Peters, M. A. (2007) Knowledge Economy, Development and the Future of Higher Education. Rotterdam: Sense Publishers.

Peters, M. A. (2009a) On the Philosophy of Open Science, The International Journal of Science in Society, 1(1), 171-198.Also available from ijy.cgpublisher.com/product/pub.187/prod.18 (accessed 26 August 2013).

Peters, M. (2009b) Open Education and the Open Science Economy, Yearbook of the National Society for the Study of Education, 108(2), 203-225.

Peters, M. A. (2013) Open Science, Philosophy and Peer Review, Educational Philosophy and Theory, DOI: 10.1080/00131857.2013.781296 dx.doi.org/10.1080/00131857.2013.781296 (accessed 26 August 2013).

Pizzigati, S. (2004) Greed and Good: understanding and overcoming the inequality that limits our lives. New York: Apex.

Poteete, A. R., Janssen, M. A. \& Ostrom, E. (2010) Working Together: collective action, the commons, and multiple methods in practice. Princeton: Princeton University Press

Raventós, D. (2007) Basic Income: the material conditions of freedom. London: Pluto.

Ravetz, J. R. (1971) Scientific Knowledge and its Social Problems. Oxford: Oxford University Press.

Ravetz, J. R. (1990) The Merger of Knowledge with Power: essays in critical science. London: Mansell.

Rees, M. J. (2003) Our Final Century: a scientist's warning: how terror, error, and environmental disaster threaten humankind's future in this century - on Earth and beyond. London: Heinemann.

Rifkin, J. (2000) The Age of Access: the new culture of hypercapitalism, where all of life is a paid- 
for experience. New York: Tarcher/Putnam.

Roberts, J. M. \& Westad, O. A. (2013) The Penguin History of the World, 6e. London: Penguin.

Roberts, K. (1982) Automation, unemployment and the distribution of income. Maastricht: European Centre for Work and Society.

Rowan-Robinson, M. \& Rudolf, A. (1985) Martin Ryle's Letter. London: Menard Press.

Rudolf, A. \& Rowan-Robinson, M. (1985) Martin Ryle's Last Testament, New Scientist, $105(14$ February), 36-37.

Schneier, B. (2012) Liars and Outliers: enabling the trust that society needs to thrive. Indianapolis: Wiley.

Scranton, P. (2012) Thinking about Work, Knowledge, Law and Property, History and Technology: an International Journal, 28(1), 93-100. DOI: 10.1080/07341512.2012.662347 .Available at dx.doi.org/10.1080/07341512.2012.662347 (accessed 26 August 2013).

Shutt, H. (2010) Beyond the Profit System: possibilities for a post-capitalist era. New York: Zed.

Whistleblowers Australia (2012) Whistleblowers Australia www.whistleblowers.org.au (accessed 26 August 2013).

Zerubavel, E. (2006) The Elephant in the Room: silence and denial in everyday life. Oxford: Oxford University Press.

ALAN COTTEY is a Fellow at the University of East Anglia. He is a physicist who has also taught on 'science, values and ethics'. He believes that it is desirable that all, specialists or not, give longterm attention to current ecological, including social, conditions. Correspondence:

a.cottey@uea.ac.uk

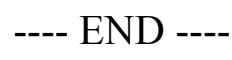

KPICE-v1-5.odt (and exported as .pdf) modified 29 August 2013 